Editorial

\title{
Resources: An Open Access Journal of Natural Resources and Their Management
}

\author{
Richard F. Kazmierczak, Jr. \\ Editor in Chief of Resources, Center for Natural Resource Economics \& Policy (CNREP), \\ Louisiana State University, 101 Woodin Hall, Baton Rouge, Louisiana 70803, USA; \\ E-Mail: rkazmierczak@agcenter.lsu.edu
}

Received: 23 April 2012 / Accepted: 24 April 2012 / Published: 24 April 2012

\begin{abstract}
Resources is an international, peer-reviewed open access journal that publishes original manuscripts, communications, review articles, and policy discussions about all aspects of natural resources and their management. The journal seeks to expand, in a rapid and rigorous way, our understanding of natural endowments, their management, and how they interact with the most personal of resources, the human community.
\end{abstract}

As Resources embarks on its first year of publication, it is the perfect time to consider how the journal can not only foster communication within the scientific community, but also how it can be a platform for expanding the world's understanding of our natural endowments, their management, and how they interact with the most personal of resources, the human community. By their very definition, resources form the living and non-living support systems for human life, encompassing everything from energy, land, water, atmosphere, wetlands, forests, wildlife and fisheries, and beyond. Unfortunately, a superficial familiarity with resource use breeds a form of contempt and hubris that only becomes obvious when serious problems arise. From the early mercury poisoning of Minimata Bay, Japan, to the collapse of the North Atlantic cod fishery, and continuing through the twin threats of increasing atmospheric temperatures and sea-levels, the scientific community has endeavored to pierce through superficial understanding to convey the seriousness of resource problems to our societies and promote the development of solutions and the political will to implement them. In most cases, we must first understand that a problem actually exists, and that the problem is complex and dynamic in its cause-and-effect characteristics, before any significant progress can be made towards the development of solutions and workable management regimes. It is in the promotion of this understanding, both 
among scientists and between scientists and the broader public, that the journal Resources can play a critical role.

But, why publish the journal Resources, and why now? In short, one of the most pressing issues in science centers on the inability to quickly get research peer-reviewed and published, especially in cases where an emerging resource problem quickly gains social and political attention, and where policy solutions are otherwise generated in a relative vacuum of information. Traditionally, scientists have worked within a system of time lags that begin with the search for project funding and continue through to the final publication of research findings, a process that often takes years to negotiate. At the same time, many scientists desire a more obvious and defined role in policy development, but this often comes only after a significant portfolio of research accomplishments has been assembled. This traditional process can leave some of the best and most creative young researchers unheard of and unheard from in policy debates. Anything that can open up this traditional process and speed communication between scientists, and between scientists and policy makers, promises to not only improve the scientific community's ability to respond to natural resource problems, but also to improve our understanding of a wide array of resource systems. These are the potential gains that Resources seeks to deliver.

So what, specifically, does Resources offer to potential contributors who have a series of traditional outlets through which they can distribute their research findings? In my opinion, speed of publication, geographic distribution, and expansion of communication. While communicating electronically is no longer a novelty, even within the traditional publication realm, Resources seeks to leverage the available technology to greatly reduce the time between the submission of a manuscript for peerreview and its availability for access and distribution, bringing the time-to-publication down from the traditional multiple months and, in many cases, years to perhaps as little as a month or two. And, Resources seeks to do this on a global scale, with its open access format greatly expanding not only the number of voices that can become involved in scientific investigations and debate, but also the number of minds that get exposed to rigorously presented arguments, evidence, and understanding. At the same time, Resources will seek to attract a wide range of manuscript types beyond the traditional scientific study, including those that focus on policy and speculative research ideas. Resources will also seek out and publish special issues that focus on topics of exceptional relevance. By broadening the kinds of articles that are published, and providing forums for discussion of the ideas contained in the articles, Resources can become a hub for scientists, policy makers, non-governmental organizations, and individuals who are not only concerned with resource use and management, but that use and management be accomplished with the best information and within a spirit of scientific inquiry and debate. I hope that you will join me in developing Resources into a journal that does something few journals actually do-positively influence the world and our societies, both for the current generation and generations to come.

(C) 2012 by the authors; licensee MDPI, Basel, Switzerland. This article is an open access article distributed under the terms and conditions of the Creative Commons Attribution license (http://creativecommons.org/licenses/by/3.0/). 